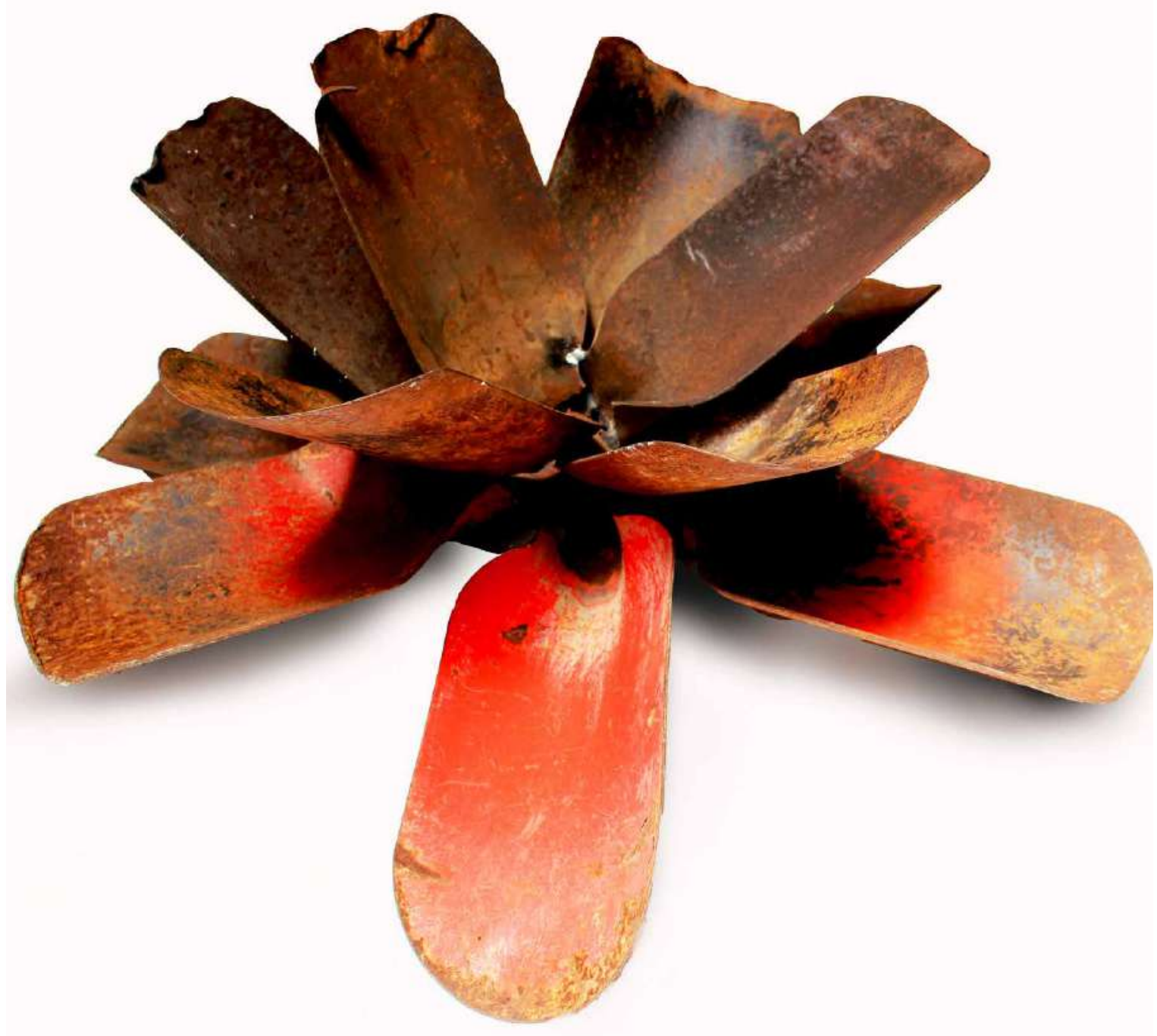

Yamith Quiroz David

Nuevas vegetaciones II

De la serie El mito de flora

Escultura, pala-dragas de hierro

$3 \times 67 \times 72 \mathrm{~cm}$

2020

Medellín 


\title{
La gobernanza para enfrentar el problema de la desaparición de personas. Experiencias de interlocución entre familiares de personas desaparecidas y autoridades gubernamentales en los estados de Coahuila y de Nuevo León (2009-2018)*
}

\author{
María Teresa Villarreal Martínez (México)**
}

\section{Resumen}

Este artículo examina el esquema de interacción entablado entre los colectivos de familiares de personas desaparecidas y las autoridades gubernamentales entre 2009 y 2018 en los estados mexicanos de Coahuila y Nuevo León, y también revisa la propuesta de participación ciudadana prevista en la Ley General en Materia de Desaparición Forzada de Personas, Desaparición Cometida por Particulares y del Sistema Nacional de Búsqueda de Personas. Mediante este estudio de caso cualitativo se responde a la cuestión sobre las oportunidades de incidencia que ofrecen ambos esquemas de participación considerados como modelos de gobernanza, uno construido desde abajo por los familiares organizados, y el otro diseñado desde arriba por el Gobierno mexicano en la forma de consejos ciudadanos. Luego de revisar la puesta en marcha de estos diferentes mecanismos de gobernanza y ante la renuencia gubernamental a implementar mecanismos participativos formales sin cortapisas, se concluye que siguen siendo indispensables los espacios creados por los colectivos de familiares de víctimas para ejercer sus derechos y para mantener vigente en la agenda pública la exigencia sobre el paradero de las personas desaparecidas.

\section{Palabras clave}

Políticas Públicas; Gobernanza; Desaparecidos; Oportunidades Políticas; Participación Política; México.

Fecha de recepción: marzo de 2020 - Fecha de aprobación: agosto de 2020

\footnotetext{
* Este artículo es parte del proyecto de investigación Sustentabilidad política y la lucha por los derechos humanos, que desarrollo desde 2018 en el Instituto de Investigaciones Sociales, Universidad Autónoma de Nuevo León, México.

** Licenciada en Ciencias de la Información. Magíster en Metodología de la Ciencia. Magíster en Administración y Alta Dirección. Doctora en Política Pública. Profesora investigadora del Instituto de Investigaciones Sociales, Universidad Autónoma de Nuevo León, México. Correo electrónico: terevima@yahoo.com - Orcid: 0000-0001-9873-4931 - Google Scholar: https://scholar.google.com/ci tations?hl=es\&user=FDK1580AAAAJ
} 


\title{
Cómo citar este artículo
}

Villarreal Martínez, María Teresa. (2020). La gobernanza para enfrentar el problema de la desaparición de personas. Experiencias de interlocución entre familiares de personas desaparecidas y autoridades gubernamentales en los estados de Coahuila y de Nuevo León (2009-2018). Estudios Políticos (Universidad de Antioquia), 59, pp. 75-97. DOI: 10.17533/udea.espo.n59a04

\section{Governance to Face the Problem of the Disappearance of People. Interlocution Experiences between Relatives of Missing Persons and Governmental Authorities in the States of Coahuila and Nuevo León (2009-2018)}

\begin{abstract}
This article examines the interaction scheme established between the groups of relatives of disappeared persons and government authorities from 2009 to 2018 in the Mexican States of Coahuila and Nuevo León. Moreover, it analyzes the proposal for citizen participation provided in the General Law on Forced Disappearance of Persons, Disappearance Committed by Individuals and the National System

[ 76 ] of Search for Persons. Through this qualitative case study, the question about the opportunities of incidence offered by both participation schemes considered as models of governance is answered, one built from bottom-up by the same family members organized, and the second designed from top-down by the government in the form of citizen councils. After reviewing the implementation of these different governance mechanisms, and in the face of the government's reluctance to implement formal participatory mechanisms without restrictions, we conclude that the spaces created by the groups of families of victims are still essential to exercise their rights and to keep the demand to know the whereabouts of the disappeared persons on the public agenda.
\end{abstract}

\section{Keywords}

Public Politics; Governance; Disappeared Persons; Political Opportunities; Political Participation; Mexico. 
La gobernanza para enfrentar el problema de la desaparición de personas...

\section{Introducción}

En las primeras dos décadas del siglo xxı en México, la desaparición de personas - ya sea forzada o perpetrada por particulares - ha motivado la creación de decenas de agrupaciones de familiares de víctimas que reclaman encontrar a sus seres queridos y conocer la verdad sobre lo sucedido. Estos colectivos han desarrollado un repertorio de acciones para introducir en la agenda pública el problema de las desapariciones y exigir la atención del problema para acceder a la justicia y la reparación.

Las respuestas estatales a este asunto han cambiado en el tiempo en diferentes entidades del país. Van desde la negación del problema hasta el trabajo conjunto con las organizaciones de familiares para la revisión de expedientes de investigación y el desarrollo de protocolos, atendiendo a la iniciativa de estos colectivos. Sin embargo, con la entrada en vigor de la Ley General en Materia de Desaparición Forzada de Personas, Desaparición Cometida por Particulares y del Sistema Nacional de Búsqueda de Personas (Cámara de Diputados, 17 de noviembre de 2017) —en adelante Ley General - a partir de enero de 2018, se ha diseñado una serie de dispositivos encaminados a regular la participación de las organizaciones de familiares en las investigaciones y en la búsqueda de sus seres queridos, una gobernanza desde arriba (top-down). En Nuevo León y Coahuila, entidades del norte de México, también se han conformado colectivos de familiares de víctimas que han emprendido acciones públicas para buscar a sus seres queridos, incluyendo formas extralegales e innovadoras de interacción con autoridades, una gobernanza desde abajo (bottom-up).

En este trabajo el caso de estudio son dos experiencias de interacción directa entre colectivos y autoridades ministeriales dentro del proceso de investigación penal. Una experiencia se registró en Nuevo León, donde la Agrupación de Mujeres Organizadas por los Ejecutados, Desaparecidos y Secuestrados de Nuevo León (Amores), asesorada por la asociación civil Ciudadanos en Apoyo a los Derechos Humanos A. C. (Cadhac), sostuvo reuniones periódicas de trabajo con la Procuraduría General de Justicia de esa misma entidad federativa entre junio de 2011 y enero de 2018; y la otra experiencia es la interlocución llevada a cabo por Fuerzas Unidas por Nuestros Desaparecidos en Coahuila (Fuundec) y el gobierno estatal. También se revisó el esbozo de gobernanza delineado en la Ley General (Cámara de Diputados, 17 de noviembre de 2017) que entró en vigor en enero de 2018. 
Se trata de un estudio cualitativo de caso, basado en datos recabados de los comunicados emitidos por los colectivos en torno a la interlocución con las fiscalías respectivas. Partiendo de la revisión de literatura sobre gobernanza, sus rasgos característicos y la crítica a esta, se analizan y comparan los mecanismos de interacción multiactorial implementados desde abajo y desde arriba en su capacidad de incidencia en el acceso a la justicia y la verdad. Se seleccionaron estas experiencias porque ambas son consideradas casos positivos por el Grupo de Trabajo sobre Desapariciones Forzadas o Involuntarias de la ONU (Consejo de Derechos Humanos, A/HRC/30/38/ Add.4 del 11 de septiembre de 2015): el de Amores en Nuevo León se califica como una «buena práctica» y el de Fuundec se señala como un «precedente positivo» el trabajo conjunto de autoridades y familiares de víctimas en la búsqueda de personas desaparecidas.

\section{Gobernanza y participación}

Los cada vez más abundantes trabajos sobre la gobernanza la definen como un proceso de dirección de la sociedad en el que participan coordinadamente el Gobierno, el sector productivo y la ciudadanía organizada o sector cívico-social, unos con más peso y capacidad de influencia que otros,

[ 78 ] según sea el desarrollo histórico de las relaciones sociales y gubernamentales en una comunidad específica (Aguilar, 2010; Subirats, 2010; Zurbriggen, 2011). En los esquemas de gobernanza realmente existentes los participantes nunca son iguales, por lo que son siempre los grupos más poderosos, los más homogéneos y los que gozan de una visión estratégica de sus propios intereses los que acumulan mayores posibilidades de éxito (Graña, 2005).

No puede hablarse de una sola gobernanza, sino de gobernanzas. En cuanto al origen de la iniciativa para generar un esquema de gobernanza, se habla de las que tienen procedencia popular, surgen desde abajo y para beneficio de los de abajo cuando en circunstancias adversas el Estado no es capaz de atender las necesidades de grupos populares o excluidos, y entonces ellos mismos se organizan para resolver su situación (Tapia, 2007). Las que surgen por iniciativa del Estado o de las grandes corporaciones económicas o de organismos internacionales, aunque promuevan las relaciones en red entre diversos actores, «mantienen esa perspectiva vertical —manifestada por sus intenciones - de legitimación del sistema social imperante, tienden a mantener el statu quo» (p. 342). En otros términos, se trata de gobernanzas desde abajo, o bien, desde arriba, por su origen, por los intereses a los que sirve y la identidad de los protagonistas. 
Una gobernanza desde arriba tiene un sentido descendente (top-down), pone el énfasis en la regulación de las interacciones mediante procedimientos y marcos legales en los que se determina quiénes son los participantes y los roles que desempeñarán, así como el alcance y los límites de la incidencia de los actores. Suele ser estadocéntrica, ya que, aunque se trate de la construcción de una red en torno a la atención de un asunto público, el nodo central - para las decisiones, acciones y relaciones - se localiza en dependencias gubernamentales, amplificando la participación de funcionarios y reduciendo las oportunidades de involucramiento de actores no gubernamentales, en particular, aquellos que no están vinculados con grupos de poder y, por tanto, suelen ser mantenidos al margen de la gestión, asignándoles roles de escasa influencia en el proceso general, por lo que no ocurre una dispersión de poder en este tipo de esquema de interacción Estado-sociedad.

Cuando el impulso y modelación de la gobernanza viene desde abajo y fuera de la esfera gubernamental, desde los grupos sociales afectados por un problema y que suelen ser invisibilizados e ignorados, entonces se trata de un movimiento ascendente (bottom-up) que busca abrirse camino para lograr colocar en la agenda pública problemas que a menudo son incómodos para el poder estatal o económico. Esta gobernanza desde abajo no pretende suplantar la labor del Estado en relación con la atención del asunto, sino que busca y exige la dedicación de recursos estatales de todo tipo - financieros, institucionales, logísticos, legales, técnicos - para la resolución del problema, de manera que haya una redistribución de poder manifestada en el respeto de derechos y garantía para su ejercicio para estos grupos sociales generalmente excluidos. En el camino para construir esta gobernanza, estos grupos de abajo van generando sus propias dinámicas de acción para hacer visible un problema, desarrollan formas emergentes y solidarias para afrontarlo, construyen redes con otros grupos afectados y hacen alianzas con otros actores individuales y organizados que tienen capacidad de influencia en los ámbitos de la toma de decisiones sobre la agenda y la acción gubernamentales.

Así, en la gobernanza se crean espacios de interacción entre actores gubernamentales y no gubernamentales, estos espacios constituyen una interfaz socioestatal (Isunza, 2005), en donde ocurre un intercambio más o menos democrático entre los participantes. La participación de actores sociales en estos espacios tiene rasgos diversos según se trate de una gobernanza planteada desde arriba o desde abajo. Si bien la participación ciudadana en la definición y atención de asuntos públicos constituye un elemento 
fundamental y condición de posibilidad para la gobernanza democrática, y puede llegar a constituir un mecanismo para el empoderamiento social (Canto, 2008), también hay que reconocer que la participación puede tener distintos alcances y efectos. Puede limitarse a la expresión de opiniones o puede llegar a vigilar y auditar la gestión de un asunto público, e incluso reorientarla cuando se desvía del objetivo de lograr el bien común; puede servir para avalar sin crítica decisiones tomadas por grupos de poder o puede abrir la puerta para que las necesidades y puntos de vista de grupos sociales excluidos sean tomados en cuenta.

La participación que ciudadaniza y hace públicos los procesos de definición de problemas públicos y diseño de políticas, como ocurre en la gobernanza desde abajo, enfrenta siempre resistencias fuertes por parte de actores acostumbrados a una participación reducida y selecta que no los obligue a dar razón a otros de las decisiones que toman, o a revelar y someter a escrutinio los motivos por los que se favorece una determinada política $y$, con ello, una determinado proyecto y futuro sociales. Estas resistencias pueden evidenciarse cuando se abren canales formales de participación, pero al mismo tiempo se limita la incidencia que pueden lograr para redireccionar la acción gubernamental a favor de la garantía de derechos de quienes suelen [ 80 ] ser excluidos y vulnerados.

En los esquemas institucionalizados de gobernanza, uno de los instrumentos más utilizados para formalizar la intervención de actores no gubernamentales en la gestión pública son los consejos ciudadanos, ya sea a escala nacional, estatal o municipal. Se trata de mecanismos orgánicos que implican la inserción de actores extragubernamentales en la estructura administrativa estatal, sin convertirse por ello en funcionarios. En ocasiones se crean consejos de manera no sistemática, pero en otras forman parte de una política pública de participación ciudadana que atraviesa toda la gestión de gobierno. En cualquier caso, el diseño institucional de los consejos ofrece diferentes posibilidades, todas relacionadas con el grado de democratización del régimen y de la sociedad, y con el tipo de ciudadanía que se pretende construir.

Sin embargo, las reglas e instituciones no marcan el límite definitivo de la participación ciudadana, pues en ausencia de canales formales los ciudadanos pueden emprender acciones colectivas que obliguen a la apertura democrática del régimen. La historia reciente muestra que esto ha sucedido en 
varias naciones, entre ellas México, en donde las movilizaciones ciudadanas -de mujeres, de indígenas, de diversidad sexual-impulsaron cambios que, de manera paulatina, llevan a la inclusión de más actores sociales en la formación de las decisiones públicas (Godois et al., 2016; Marti i Puig, 2007; Saldivia Menajovsky, 2017). Esto también se ha registrado ante el problema concreto de la desaparición de miles de personas.

En este texto se verá cómo, ante la indolencia estatal, colectivos de familiares de víctimas en diferentes partes del país — en experiencias separadas, pero en la misma época- abrieron vías de acceso a los espacios de toma de decisiones para introducir en la agenda pública el problema de la desaparición de personas. Entre el abanico de acciones desplegadas por estos colectivos, el análisis que aquí se ofrece se enfoca en la forma como los familiares de víctimas organizados obligaron a las autoridades a aceptarlos como interlocutores en la tarea de la procuración de justicia.

Este trabajo toma como casos de estudio las experiencias de interlocución entre familiares de personas desaparecidas y autoridades gubernamentales en los estados de Coahuila y de Nuevo León. Se considera que la interlocución desarrollada constituye un esquema de gobernanza impulsada desde abajo por las víctimas y organismos de derechos humanos, que luego ha sido tomada por las instituciones estatales para regularla y modelarla a través de la Ley General y de los instrumentos que de ella se derivan, que incluyen protocolos acerca de cómo debe ser la participación de los familiares de las víctimas en las diferentes instancias del Sistema Nacional de Búsqueda de Personas (SNBP) y de los sistemas estatales.

Se vuelve entonces fundamental revisar el diseño de estos mecanismos de participación, así como observar el camino que tome la participación de familiares de víctimas más allá de los esquemas legales formalizados.

\section{La participación desde abajo en el caso de la desaparición de personas}

La desaparición de personas no es un problema nuevo en México, está documentada su prevalencia desde las décadas de 1960 y 1970 como una estrategia del Estado contra opositores políticos (Doyle, 2006, febrero 26). En esa época se crearon organizaciones de familiares de víctimas que más de cuarenta años después siguen trabajando para encontrar a los 
desaparecidos durante la llamada «Guerra Sucia» y que reclaman el derecho a la verdad, y la reparación. ${ }^{1}$

Desde la década de 1990, en un contexto marcado cada vez más por la violencia, tanto de grupos delincuenciales como la producida por la misma acción gubernamental en el combate al crimen organizado, la desaparición de personas ha aumentado aceleradamente hasta sumar decenas de miles de víctimas. No se conoce con exactitud la cifra total de personas que han sido desaparecidas en los últimos veinte años en México - sean desapariciones forzadas o perpetradas por particulares-. En el informe más reciente proporcionado por la Secretaría de Gobernación (2020, julio 13) se indicó que había 73218 personas que continuaban sin ser localizadas, de las cuales $97 \%$ desapareció entre 2006 y mediados de 2020.

En este siglo xxı también se han multiplicado los grupos de familiares de personas desaparecidas que se organizan para realizar acciones públicas para visibilizar el problema, demandar la localización de las víctimas y exigir justicia. En 2013 se identificaron 16 colectivos distribuidos en diez entidades federativas (Villarreal, 2014). A mediados de 2020 ya suman más

[ 82 ] de 70 los colectivos con presencia en al menos 30 de las 32 entidades federativas. Tan solo el Movimiento por Nuestros Desaparecidos en México conforma una red de más de 60 colectivos. Otras redes nacionales son Fuerzas Unidas por Nuestros Desaparecidos en México, Red Eslabones por los Derechos Humanos, Red de Enlaces Nacionales y la Campaña Nacional contra la Desaparición Forzada, además de grupos de familiares que no están vinculados a red alguna (MNDM, s. f.; Campaña Nacional contra la Desaparición Forzada, 2019, marzo 25).

Ante la indolencia y falta de capacidades de los gobiernos - federal, estatales y municipales - para encontrar a las personas desaparecidas, sancionar a los responsables y reparar los daños, estos colectivos de familiares de víctimas han levantado la voz para demandar al Estado que reconozca el problema y actúe de acuerdo a sus obligaciones como garante de los derechos a la verdad, a la justicia y a la reparación.

\footnotetext{
${ }^{1}$ Algunas son Comité Eureka, Asociación de Familiares de Detenidos Desaparecidos y Víctimas de Violaciones a los Derechos Humanos en México (Afadem), Hijos por la Identidad y la Justicia, contra el Olvido y el Silencio (H.I.J.O.S) y la Asociación Civil Nacidos en la Tempestad.
} 
Las acciones emprendidas por estos colectivos orientadas hacia el tratamiento de la desaparición de personas como un problema público pueden agruparse en los siguientes rubros: registro y documentación de casos, denuncia pública, diálogo con autoridades, impulso de marcos legales, creación de redes (Villarreal, 2014), búsqueda de desaparecidos y construcción de la memoria. En cada categoría los familiares de las víctimas han desplegado su creatividad a fin de atender a la necesidad de saber la verdad. De este abanico de actividades, este trabajo se enfoca en el diálogo con autoridades, ya que abre la posibilidad al intercambio de información entre ciudadanos y Estado, y a la actuación conjunta para afrontar el problema, en lo que puede considerarse una interfaz socioestatal (Isunza, 2005), un espacio de intercambio y conflicto en el que actores sociales y estatales se relacionan intencionadamente y confrontan sus proyectos y estrategias.

Los intentos por entablar un diálogo parten de los colectivos hacia las autoridades — generalmente del Poder Ejecutivo de la entidad federativa一, pero no siempre tienen éxito y generalmente son encuentros esporádicos, a veces únicos — por la indiferencia gubernamental—o sin continuidad — por la carencia de sistematicidad o método-.

La primera experiencia de interlocución formal con autoridades, impulsada directamente por los grupos de familiares de víctimas de desaparición se registró en el estado de Coahuila en 2009. El 18 de diciembre, familiares de 21 personas que desparecieron en distintos eventos, sostuvieron una reunión con el fiscal estatal para conocer el avance en la investigación sobre el paradero de sus seres queridos (Durón, 2017, mayo 8). En este encuentro no recibieron información, pero pactaron reuniones periódicas para revisar los casos. Se efectuaron mesas de trabajo en los primeros meses de 2010, pero al no ver avances y ante el desinterés del fiscal que canalizó la atención de los casos a funcionarios de menor jerarquía, los familiares suspendieron la interlocución y optaron por dirigirse a la ciudad de México para hablar con autoridades federales. Estos familiares integraron el colectivo Fuerzas Unidas por Nuestros Desaparecidos en Coahuila (Fuundec). A lo largo de diez años, con el acompañamiento del Centro Diocesano para los Derechos Humanos «Fray Juan de Larios», A. C., emprendieron diversidad de acciones: documentación de casos, denuncia pública, búsqueda en campo, vinculación con organismos internacionales y la interlocución intermitente con funcionarios estatales —incluido el gobernador- y federales. 
En diversos momentos Fuundec ha decidido suspender el diálogo cuando el gobierno estatal no ha dado muestras de trabajar con seriedad en la búsqueda de las víctimas, pero luego han reanudado los encuentros (Turati, 2012, diciembre 19; Pacheco, 2014, febrero 10). Algunas reuniones son plenarias en las que funcionarios y familiares de víctimas definen agendas de trabajo y se revisa la labor de las dependencias en materia de desapariciones; otras reuniones son solamente entre la Procuraduría o Fiscalía estatal y cada una de las familias para presentar el avance de las averiguaciones. En ellas estaban presentes el secretario general de Gobierno, el fiscal general, el fiscal ministerial y los ministerios públicos encargados de los casos. En algunas participó el gobernador en turno, quien se enteró tanto de las desapariciones como de las omisiones e ineficiencias de los ministerios públicos en las investigaciones.

Uno de los principales logros de estos encuentros es el reconocimiento del Gobierno estatal de la existencia del problema de la desaparición de personas en Coahuila y la necesidad de que se incluya en la agenda gubernamental para su atención y solución. Esta experiencia también ha sido punto de partida para la creación de otros espacios de diálogo de alto nivel como el Grupo de Trabajo Autónomo en el que participan la ONU, el [ 84 ] Gobierno estatal y Fuundec. Este Grupo de Trabajo se planteó como objetivo la implementación en Coahuila de las recomendaciones emitidas por el GTDFI de la ONU.

En retrospectiva, esta interlocución con el Gobierno estatal permitió la construcción de una agenda institucional de trabajo para enfrentar el problema de las desapariciones en Coahuila, se logró la aprobación de marcos legales en materia de desaparición y la puesta en marcha de un programa de atención para las familias de las víctimas, así como la organización de foros públicos con la participación de expertos en los que se analizó el problema, lo que contribuyó a visibilizarlo y sensibilizar a la sociedad; sin embargo, en el esclarecimiento de los casos concretos de desaparición los resultados fueron nulos (Sánchez, Pérez y Verástegui, 2018).

Cuando en 2009 en Coahuila inició esta experiencia de interlocución, en Nuevo León eran recurrentes las manifestaciones públicas de familiares de personas desaparecidas que exigían respuestas al Gobierno estatal. En septiembre de ese año, un grupo de familiares inició un plantón indefinido frente al Palacio de Gobierno (Rodríguez, 2009, septiembre 2). A fin de que 
retiraran el plantón, la Procuraduría General de Justicia de Nuevo León ofreció establecer una mesa de trabajo para informar los avances de los casos. Primero, se efectuaron reuniones semanales, luego quincenales, después mensuales y bimestrales, hasta que dejaron de asistir las autoridades encargadas y no hubo avances significativos en las investigaciones. Este esquema de interlocución planteado desde arriba se agotó por la falta de participación de las mismas autoridades que lo propusieron y por el trato revictimizante que daban a los familiares que acudían para saber el paradero de sus seres queridos. Inconformes con los resultados y el trato recibido, los familiares decidieron suspender la interlocución y dieron a conocer su postura mediante un oficio enviado al gobernador en agosto de 2010 (Cadhac, 2011). Desde 2009, algunos de estos casos de desaparición llegaron a la organización Cadhac, la cual empezó a brindar a los familiares apoyo jurídico y psicosocial, pero sin conseguir que las autoridades atendieran el problema.

En 2011 el problema de las ejecuciones y desapariciones de decenas de miles de personas a lo largo del territorio nacional se visibilizó con las caravanas realizadas por el Movimiento por la Paz con Justicia y Dignidad (MPJD), encabezado por el poeta Javier Sicilia y el activista Emilio Álvarez Icaza. El 7 de junio llegó a Monterrey la Caravana del Consuelo que congregó a cientos de personas en la plaza del Colegio Civil para escuchar los testimonios de personas que buscaban infructuosamente a sus familiares desaparecidos sin apoyo alguno de las autoridades. Al finalizar el acto, Sicilia y Álvarez propusieron ir a ver al procurador estatal para exigirle respuestas. A la medianoche, el entonces procurador Adrián de la Garza — quien había asumido el cargo cinco meses antes-, recibió a un grupo de familias de personas desaparecidas, a representantes de Cadhac y a los integrantes del MPJD, y se comprometió a mostrar avances periódicos en el tema de desapariciones (Cadhac, 2012).

Así dio inicio un proceso de interlocución entre la Procuraduría General de Justicia del Estado de Nuevo León y los familiares de personas desaparecidas asesorados por Cadhac — a partir de 2013 el grupo de familiares adoptó el nombre de Agrupación de Mujeres Organizadas por los Ejecutados, Desaparecidos y Secuestrados de Nuevo León (Amores) - , que continuó hasta enero de 2018 mediante reuniones periódicas en las que se revisaban los expedientes de los casos, se hacían propuestas y se tomaban acuerdos para el avance de las investigaciones. Entre 2011 y enero de 2018 se realizaron treinta reuniones con una frecuencia bimestral. A diferencia del caso de Coahuila, en 
Nuevo León las reuniones de trabajo se realizaron de manera ininterrumpida durante seis años. Se trató también de una iniciativa surgida desde abajo, que logró que las autoridades se sentaran no solo a dialogar, sino que sometieran su trabajo a la revisión y valoración de los familiares de las víctimas, quienes también hacían sugerencias para avanzar en las averiguaciones. Días antes de cada encuentro, Cadhac emitía un comunicado que se difundía en los medios y en las redes sociales en Internet para convocar a la sociedad a que acompañara a los familiares en marcha hacia las oficinas de la Procuraduría. Al finalizar, Cadhac emitía otro comunicado para dar a conocer si hubo algún avance o cuáles eran las dificultades encontradas. ${ }^{2}$

La forma de llevar a cabo las reuniones cambió luego de los primeros tres encuentros que llegaban a prolongarse por más de doce horas continuas, ya que de manera plenaria se revisaban los expedientes, los ministerios públicos de cada caso presentaban el trabajo realizado y los familiares emitían su opinión. A partir de la cuarta reunión, en octubre de 2011, el trabajo de revisión se organizó en mesas simultáneas, agrupando los casos de acuerdo al agente del Ministerio Público que tenía asignadas las investigaciones. Inmediatamente después de las mesas simultáneas se realizaba una reunión plenaria en la que se presentaba la síntesis y acuerdos de cada mesa (Cadhac, 2012). Esta manera de distribuir el análisis de expedientes agilizó el trabajo, de manera que la duración de las reuniones se redujo a la mitad.

Mediante la interlocución periódica con la Procuraduría General de Justicia del Estado de Nuevo León, Cadhac y los familiares de víctimas que conforman Amores detectaron que los recursos humanos y tecnológicos con los que contaba la Policía Federal Ministerial eran insuficientes para acometer con efectividad la investigación de campo ante la cantidad ingente de casos de desaparición (Cadhac, 2013). Para coadyuvar a la creación de mecanismos de búsqueda, en mayo de 2013 se organizaron mesas de trabajo para la elaboración del Procedimiento de Búsqueda e Investigación de Personas Desaparecidas, en la que participaron también expertos. ${ }^{3}$ El Protocolo estableció la creación de una Unidad de Búsqueda Urgente, que empezó a operar en marzo de 2014 con el nombre de Grupo Especializado de Búsqueda

\footnotetext{
${ }^{2}$ Los comunicados emitidos para cada una de las 30 reuniones pueden consultarse en Cadhac (s. f.).

${ }^{3}$ Fernando Coronado, representante de la Comisión de Derechos Humanos del Distrito Federal; Alan García, de la Oficina en México del Alto Comisionado de las Naciones Unidas para los Derechos Humanos; Luis Eduardo Zavala, del Tecnológico de Monterrey; y Alejandro Valencia, consultor independiente en materia de Derechos Humanos de Colombia.
} 
Inmediata (GEBI), con el objetivo de abocarse a la búsqueda y localización de personas desaparecidas en las primeras 72 horas de ocurridos los hechos. Una valoración sobre el primer año de operaciones del GEBI —de marzo 2014 a marzo 2015- mostró una eficacia en 88\% de los casos que recibió (Cadhac, 2015). Sin embargo, en un nuevo monitoreo realizado por Cadhac publicado a principios de 2017 se encontró que la eficacia del GEBI había disminuido considerablemente y que incluso se había alejado del objetivo principal que era la puesta en marcha del procedimiento.

Luego de seis años de interlocución directa entre familiares de víctimas y la Procuraduría General de Justicia del Estado de Nuevo León en la que se llevaron a cabo 30 reuniones, se revisaron expedientes correspondientes a 236 personas desaparecidas. En ese periodo se localizó a 169 personas -75 vivas y 94 fallecidas e identificadas mediante prueba de ADN—, la Procuraduría consignó a 63 personas como presuntas responsables y el Poder Judicial sentenció a 22, de los cuales 18 eran policías (Cadhac, 2017, agosto 30).

Ante el agotamiento de este mecanismo de trabajo, desde 2018 Cadhac y Amores emprendieron un cambio en la estrategia y «se optó por trabajar en los casos de manera individual, entablando comunicación constante con la familia de la persona desaparecida, la autoridad correspondiente a la investigación y la o el abogado de CADHAC que lleva el caso» (Cadhac, 2019, p. 21).

En Nuevo León, además del grupo Amores, hay otro colectivo de familiares Fuerzas Unidas por Nuestros Desaparecidos en Nuevo León (Fundenl), que desde 2012 ha emprendido acciones públicas de denuncia del problema, documentación de casos, búsqueda en campo y también reuniones de trabajo con la Procuraduría. Sin contar con el acompañamiento formal de alguna organización de derechos humanos, entre agosto de 2014 y julio de 2015, Fundenl promovió la realización de mesas de trabajo con la Procuraduría General de Justicia del Estado de Nuevo León para evaluar el avance en la resolución de ocho casos de desaparición. Luego de diez meses de reuniones, el colectivo emitió un comunicado donde valoró como insuficiente el trabajo de la autoridad: de la propuesta de 52 diligencias para que el Ministerio Público realizara interrogatorios que ayudaran a recabar más datos, la autoridad solo efectuó 9. En cuanto al desahogo de pruebas periciales, de un total de 45 seguían pendientes 37 (Fundenl, 2015, julio 9). 
Ante la ineficacia de la Procuraduría, Fundenl presentó quejas ante la Comisión Estatal de Derechos Humanos que se tradujeron en cuatro recomendaciones -N. .96 del 28 de febrero de 2017; N. 7 del 28 de febrero de 2017; N. 15 del 6 de abril de 2017; N. 18 del 25 de mayo de 2017- en las que el ombudsman local señaló a la Procuraduría como responsable de la dilación de investigaciones y de no respetar el derecho de acceso a la justicia.

\section{La regulación de la gobernanza desde arriba}

Si los mecanismos de interlocución desarrollados en Coahuila y Nuevo León constituyen casos de gobernanza desde abajo, ahora se examina la propuesta de gobernanza desde arriba que está contenida en la Ley General (Cámara de Diputados, 17 de noviembre de 2017) que entró en vigor en enero de 2018.

En el ámbito nacional, este marco legal prevé un mecanismo institucionalizado de participación para los familiares de víctimas a través del Consejo Nacional Ciudadano (CNC), órgano de consulta del Sistema Nacional de Búsqueda de Personas (SNBP) compuesto, según establece el artículo 60, por cinco familiares de víctimas, cuatro especialistas en derechos

[ 88 ] humanos y búsqueda de personas desaparecidas, y cuatro representantes de organismos civiles de derechos humanos. De acuerdo al artículo 45, el SNBP es el órgano superior que articula los esfuerzos en la búsqueda y localización de las personas desaparecidas, y está integrado por 39 funcionarios públicos federales y estatales, y tres representantes del CNC. De los tres últimos, solo uno proviene de los colectivos de familiares de víctimas. Así, desde el diseño de su integración se reducen las posibilidades de intervención directa de los colectivos en el SNBP y su presencia queda diluida entre funcionarios y algunos expertos. Esta reducción de las oportunidades de intervención para los grupos tradicionalmente excluidos suele ocurrir en mecanismos de participación diseñados desde arriba.

Además de esta composición con una presencia limitada de los familiares de víctimas, el peso del CNC en las decisiones que toma el SNBP es mínimo, ya que el artículo 46 señala que las sesiones del SNBP serán válidas tan solo con la asistencia de la mayoría de sus integrantes, sin especificar que sea necesaria la presencia de los representantes del CNC. Las resoluciones se toman por mayoría de votos y, en caso de empate, el presidente del consejo tiene voto de calidad. 
Entre las atribuciones del CNC están el seguimiento y evaluación del trabajo desarrollado por la Comisión Nacional de Búsqueda (CNB), un órgano administrativo desconcentrado de la Secretaría de Gobernación encargado de ejecutar las acciones de búsqueda de personas desaparecidas y no localizadas - Programa Nacional de Búsqueda - en todo el territorio nacional, impulsar la vinculación entre autoridades para las tareas de búsqueda y establecer mecanismos de comunicación, participación y evaluación de la sociedad civil y familiares que coadyuven al logro de los objetivos de la CNB.

El CNB puede emitir recomendaciones, opiniones y propuestas, hacerlas llegar a los miembros del SNBP para que las tomen en cuenta en sus decisiones, pero sin obligación alguna de seguirlas, solamente justificar la negativa. Sin embargo, las recomendaciones mencionadas solo se refieren a la integración, lineamientos y operación de la CNB, no acerca del trabajo de las otras dependencias que conforman el SNBP, como es la Fiscalía General de la República, encargada de la investigación de delitos a través de la Fiscalía Especializada. Las atribuciones del CNC se refieren a proponer, opinar, solicitar información, dar seguimiento, contribuir a la promoción de políticas públicas para atender las desapariciones, contribuir a la participación de familiares de víctimas, informar a las autoridades sobre irregularidades detectadas y emitir recomendaciones sobre el trabajo de la CNB. De estas atribuciones, las que podrían favorecer una participación encaminada al control de la gestión y las políticas y programas derivados de la Ley General son las dos últimas. La Ley prevé que en cada entidad federativa se establezcan Comisiones Locales de Búsqueda y Consejos Ciudadano, con atribuciones similares a las del orden federal.

Para la investigación de los hechos que puedan constituir delito en torno a la desaparición de personas, la Ley General creó una Fiscalía Especializada y planteó que cada entidad federativa debe crear sendas fiscalías. De este modo, se separaron las tareas de investigación del delito de la labor de búsqueda de personas desaparecidas. Anteriormente, las procuradurías o fiscalías federales o estatales se encargaban de la persecución del delito, pero no quedaba claro quién buscaba a las personas desaparecidas, de manera que podría ocurrir que encontraran a los responsables de una desaparición y cerraran el caso, aunque la víctima no fuera localizada.

Sobre la participación directa de familiares de víctimas en las tareas de investigación y la búsqueda de desaparecidos, la Ley General indica que 
se realizarán de acuerdo a los protocolos que se aprueben en la materia, es decir, este involucramiento que venía ocurriendo al ritmo de la creatividad e iniciativas de los colectivos que presionaban para que las autoridades les permitieran dar seguimiento a las investigaciones, proponer diligencias y nuevas líneas de trabajo es ahora normado y se establece como obligación respetar el derecho a participar.

El 16 de julio de 2018 la Conferencia Nacional de Procuración de Justicia aprobó el Protocolo Homologado de Investigación para los Delitos de Desaparición Forzada de Personas y Cometida por Particulares, después de un proceso en el que fue puesto a consideración de colectivos de familiares de víctimas y de organismos de derechos humanos nacionales e internacionales. En este documento se dedica un apartado a plantear la participación de familiares en las averiguaciones como un derecho a recibir información, proponer diligencias, opinar sobre las acciones de las autoridades, acceder a los expedientes de investigación y solicitar la intervención de peritos independientes. Estos derechos son reconocidos en el artículo 138 de la Ley General, constituyen una novedad que implicó la elaboración de este protocolo que sustituyó a uno anterior emitido en 2015 y que no contemplaba participación alguna de los familiares de víctimas (Fiscalía General de la [ 90 ] República, 15 de octubre de 2015).

El protocolo de 2018, vigente en la actualidad, sugiere que el Ministerio Público acuerde con las víctimas indirectas reuniones de seguimiento y de presentación de avances en la investigación. En estas reuniones, los familiares de las víctimas pueden solicitar la realización de diligencias y el Ministerio Público debe dar respuesta a la solicitud en un plazo de tres días. Se indica que la comunicación entre funcionarios y víctimas indirectas debe ser continua y permanente, y se establece que es obligación estatal brindar protección a los familiares de víctimas que puedan correr algún riesgo durante la investigación, evitar la revictimización y proporcionar apoyo médico y psicosocial. Puede verse alguna similitud entre lo que establece el protocolo y lo que ya venía ocurriendo desde 2009 en Coahuila y desde 2011 en Nuevo León, con la interlocución entre familiares de víctimas y procuradurías.

En mayo de 2020, la Secretaría de Gobernación presentó el Protocolo Homologado para la Búsqueda de Personas Desaparecidas y No Localizadas, y lo puso a consideración de los colectivos de familiares de víctimas y organizaciones civiles para su revisión. Este protocolo incluye un apartado 
sobre la participación de familiares en las tareas de búsqueda. Se reconoce que esta participación amplia es un derecho, más no una obligación de los familiares, ya que la búsqueda de personas es una tarea obligatoria del Estado. En todo momento, prevalece la obligación de las autoridades de mantener informados a los familiares sobre el avance en las tareas de búsqueda. También en este caso, el protocolo abreva de las experiencias de trabajo conjunto desarrolladas en diferentes partes del país entre organizaciones de familiares de víctimas y autoridades.

\section{La puesta en práctica de una gobernanza regulada}

Analizar la implementación de la gobernanza diseñada desde arriba en los mecanismos legales es prematuro todavía, ya que en el ámbito federal y más aún en las entidades federativas hay un atraso considerable en la creación de los órganos encargados de la búsqueda de víctimas y de la investigación de los delitos de desaparición forzada y cometida por particulares. Por eso este apartado es más una aproximación a los pasos iniciales de esta forma institucionalizada de interfaces Estado-sociedad ante el problema de las desapariciones.

La gobernanza regulada es el esquema de interacción entre Gobierno y sociedad en un asunto determinado, pautado mediante normas y procedimientos que fijan roles, atribuciones, derechos y límites. El involucramiento de los colectivos de familiares de víctimas de desaparición en los procesos de investigación penal había sido una experiencia modelada sobre la marcha por los mismos participantes, pues cuando en 2009 y 2011 iniciaron la interlocución formal con autoridades ministeriales en los casos de Coahuila y Nuevo León, aun no se aprobaba la Ley General de Víctimas del 9 de enero de 2013 que definió por primera vez en México la categoría jurídica de víctima directa e indirecta y les reconoció derechos, por lo que las experiencias de diálogo formal impulsadas desde abajo se realizaron sin tener ese marco legal como referente. Más bien podría considerarse que fue al revés, a partir de las múltiples acciones emprendidas por las víctimas organizadas es que se logró el reconocimiento jurídico de su identidad y de sus derechos.

En las entidades federativas, el proceso de integración de las Comisiones Locales de Búsqueda (CLB) ha sido accidentado en algunos casos, además de realizarse con retraso, pues la Ley General indica que debían quedar 
integradas a partir de los noventa días de la entrada en vigor de la norma, es decir, el 16 de abril de 2018, sin embargo, en esa fecha aún no había una sola CLB instalada. En junio de 2019 había 24 de 32 comisiones instaladas, 18 de ellas con titular (Presidencia de la República, 24 de junio de 2019). Un año después, 25 comisiones locales contaban con titular, una tenía un delegado, otra un encargado de despacho y 4 continuaban acéfalas (Secretaría de Gobernación, 12 de junio de 2020). En enero de 2020, solamente 7 comisiones locales contaban con Consejo Ciudadano - Coahuila, Tamaulipas, Hidalgo, Veracruz, Puebla, Morelos y la Ciudad de México- (MNDM, 2020, enero 16), por tanto, aún no existen los espacios institucionalizados de participación de los familiares de víctimas.

La creación de fiscalías especializadas en las entidades federativas también presenta un retraso considerable pues, aunque la Ley General prevé en el tercero transitorio que deberán entrar en funciones a los treinta días de entrada en vigor de la Ley —febrero 2018—, para enero de 2020 todavía faltaban siete estados por conformar estas fiscalías (MNDM, 2020, enero 16). Sobre el Protocolo Homologado de Investigación para los Delitos de Desaparición Forzada de Personas y Cometida por Particulares vigente desde julio de 2018 que prevé que las fiscalías promuevan reuniones de trabajo con

[ 92 ] familiares victimas para que participen en el proceso de investigación penal, no hay datos sobre cómo está ocurriendo la implementación. En cuanto al Protocolo Homologado para la Búsqueda de Personas Desaparecidas y No Localizadas que prevé el involucramiento amplio de los familiares en las tareas de búsqueda de sus seres queridos desaparecidos, se encontraba a mediados de agosto de 2020 en fase de consulta y revisión con las organizaciones familiares y la academia. Será un trabajo posterior revisar y valorar la implementación de estos protocolos a la luz del ejercicio de derechos de las víctimas.

\section{Conclusiones}

Los familiares de las personas desaparecidas, ellos mismos víctimas indirectas de este delito, son quienes han tenido que ingeniárselas para abrir brecha en medio de la indiferencia social y la indolencia gubernamental para visibilizar el problema, evidenciar que los procedimientos existentes de procuración de justicia no funcionan y que los marcos legales no garantizaban los derechos de las víctimas ni la búsqueda de la verdad. Es esta lucha de las víctimas organizadas, específicamente para el caso de las personas 
desaparecidas, la que se considera un caso de gobernanza desde abajo basada en la participación no institucionalizada para exigir cuentas, monitorear el trabajo de las autoridades, aplicar sanciones simbólicas y realizar propuestas legales y de política pública.

Entre las acciones emprendidas por algunos de estos grupos destaca la interlocución formal con autoridades para dar seguimiento puntual a casos concretos de personas desaparecidas, con la finalidad de revisar los avances de las investigaciones ministeriales y demandar que no solo se encuentre y sancione a los responsables, sino, sobre todo, que se busque a las víctimas. La participación de los colectivos en el proceso de investigación de las procuradurías es una innovación obtenida mediante la presión de los familiares organizados y asesorados por organismos civiles profesionales dedicados a la defensa y promoción de los derechos humanos. Este logro tiene que ver con las oportunidades que ofrece el contexto y la capacidad de incidencia política.

En cuanto a la gobernanza diseñada desde arriba mediante la Ley General, su implementación ha sido lenta, incluso se han rebasado por mucho los plazos legales para la creación de estas instancias. Por tanto, para valorar la implementación de esta interfaz socioestatal de gobernanza diseñada desde arriba, habrá que esperar un tiempo. Por lo pronto, el retraso en su realización es un síntoma de las resistencias que hay para reconocer y garantizar el derecho de las víctimas a la verdad y a tener pleno acceso y capacidad de actuar en todas las etapas de la investigación. Más allá de impulsar el rol de testigos y fuentes de información, en una investigación eficaz se trata también de garantizar a las víctimas indirectas el acceso a información, incluir en las decisiones su punto de vista, respetar el derecho a hacer planteamientos, aportar pruebas y formular alegatos desde el inicio de las investigaciones hasta el proceso ante tribunales (ONU, A/HRC/27/56 del 27 de agosto de 2014).

En los mecanismos previstos en la Ley General los familiares tienen formalmente oportunidades escasas de influir en la toma de decisiones sobre el diseño de acciones gubernamentales encaminadas a buscar a las personas desaparecidas, ya que su participación en el Sistema Nacional de Búsqueda de Personas es proporcionalmente menor en comparación con los funcionarios de los distintos órdenes de gobierno y sus atribuciones no favorecen la asunción de un control ciudadano alterno de las políticas y programas emanados de ese sistema. Si en el esquema de gobernanza 
desde abajo los familiares de las víctimas eran protagonistas e impulsores de ejercicios de rendición de cuentas por parte de los ministerios públicos, ahora, en los consejos consultivos ciudadanos adoptan más un papel de testigos de las acciones de la autoridad, con posibilidad de emitir recomendaciones que en ningún caso tienen carácter de observancia obligatoria.

El abordaje del problema de la desaparición de personas ha de encaminarse a encontrar a las víctimas, esclarecer la verdad y reparar el daño infligido. Pero ante una experiencia de años de indolencia gubernamental y la actual resistencia a implementar la participación institucionalizada de las víctimas indirectas en los procesos de búsqueda e investigación, se vuelve indispensable continuar con ejercicios de gobernanza impulsada desde abajo por los mismos colectivos y sus redes para llevar a cabo la vigilancia y control eficaz de la acción gubernamental, colocar a las víctimas en el centro, que se atiendan sus intereses y que se garanticen sus derechos.

\section{Referencias bibliográficas}

1. Aguilar, Luis F. (2010). El futuro de la gestión pública y la gobernanza después de la crisis. Frontera Norte, 22 (43), pp. 187-213. http://doi.org/10.17428/rfn.v22i43.876

2. Campaña Nacional contra la Desaparición Forzada. (2019, marzo 25). Comunicado de la Campaña Nacional Contra la Desaparición Forzada en México a más de 100 días del Gobierno encabezado por el Presidente Andrés Manuel López Obrador. Comité Cerezo México. Recuperado de https://www.comitecerezo.org/spip. php?article3235\&lang $=\mathrm{es}$

3. Canto, Manuel. (2008). Gobernanza y participación ciudadana en las políticas públicas frente al reto del desarrollo. Política y Cultura, 30, pp. 9-37.

4. Ciudadanos en Apoyo a los Derechos Humanos A. C. (Cadhac). (2011). Informe Anual 2010. Recuperado de https://cadhac.org/2010.pdf

5. Ciudadanos en Apoyo a los Derechos Humanos A. C. (Cadhac). (2012). Informe Anual 2011. Recuperado de https://cadhac.org/2011.pdf

6. Ciudadanos en Apoyo a los Derechos Humanos A. C. (Cadhac). (2013). Informe Anual 2012. Recuperado de https://cadhac.org/2012.pdf

7. Ciudadanos en Apoyo a los Derechos Humanos A. C. (Cadhac). (2015). Grupo Especializado de Búsqueda Inmediata. A un año de su creación (Marzo 2014-Marzo 2015). Monterrey: Cadhac.

8. Ciudadanos en Apoyo a los Derechos Humanos A. C. (Cadhac). (2017, agosto 30). 10 años de búsqueda de personas desaparecidas en Nuevo León. Recuperado de https://cadhac.org/10-anos-de-busqueda-de-personas-desaparecidas-en-nuevo-leon/ 
La gobernanza para enfrentar el problema de la desaparición de personas...

9. Ciudadanos en Apoyo a los Derechos Humanos A. C. (Cadhac). (2019). Informe Anual 2018. Recuperado de https://cadhac.org/wp-content/uploads/2019/05/ Informe-Anual-2018.pdf

10. Ciudadanos en Apoyo a los Derechos Humanos A. C. (Cadhac). (s. f.). Comunicado. Recuperado de http://cadhac.org/category/comunicado/

11. Doyle, Kate. (2006, febrero 26). Informe Documenta sobre 18 años de «Guerra Sucia» en México. The National Security Archive. Recuperado de https://nsarchive2. gwu.edu//NSAEBB/NSAEBB180/index2.htm

12. Durón, Luis (2017, mayo 8). Fuundec, el origen de la lucha. Zócalo. Recuperado de https://www.zocalo.com.mx/new_site/articulo/fuundec-el-origen-dela-lucha

13. Fuerzas Unidas por Nuestros Desaparecidos en Nuevo León (Fundenl). (2015, julio 9). Fundenl presenta evaluación hecha al gobierno de nuevo león en materia de investigación sobre desaparición de personas. Recuperado de http://fundenl.org/1336/

14. Godois de Castro Tavares, Aline et al. (2016). Movimientos de mujeres y lucha feminista en América Latina y el Caribe. Buenos Aires: Clacso.

15. Graña, Francois (2005). Globalización, gobernanza y Estado Mínimo: pocas luces y muchas sombras. Polis, 12, Recuperado de https://journals.openedition.org/ polis/5563

16. Isunza Vera, Ernesto (2005) Interfaces socioestatales y proyectos políticos. La disputa entre rendición de cuentas y participación ciudadana desde la perspectiva de la igualdad compleja. En: Monsiváis, Alejandro (comp.). Políticas de transparencia: ciudadanía y rendición de cuentas (pp. 17-30). México, D. F.: IFAI, Cemefi. Recuperado de http://biblioteca.udgvirtual.udg.mx/jspui/handle/123456789/1014

17. Marti i Puig, Salvador (ed.). (2007). Pueblos indígenas y política en América Latina. El reconocimiento de sus derechos y el impacto de sus demandas a inicios del siglo XXI. Barcelona: Cidob.

18. México. Cámara de Diputados. Ley General de Víctimas. (9 de enero de 2013). Recuperado de http://www.diputados.gob.mx/LeyesBiblio/pdf/LGV_030117.pdf

19. México. Cámara de Diputados. Ley General en materia de Desaparición Forzada de Personas, Desaparición Cometida por Particulares y del Sistema Nacional de Búsqueda de Personas. (17 de noviembre de 2017). Recuperado de http://www. diputados.gob.mx/LeyesBiblio/pdf/LGMDFP_171117.pdf

20. México. Comisión Estatal de Derechos Humanos. Recomendación N.o 6. (28 de febrero de 2017). Recuperado de https://www.cndh.org.mx/sites/all/doc/ Recomendaciones/2017/Rec_2017_006.pdf

21. México. Comisión Estatal de Derechos Humanos. Recomendación N. ${ }^{\circ}$ 7. (28 de febrero de 2017). Recuperado de https://www.cndh.org.mx/sites/default/files/doc/ Recomendaciones/2017/Rec_2017_007.pdf 
22. México. Comisión Estatal de Derechos Humanos. Recomendación N. ${ }^{\circ}$ 15. (6 de abril de 2017). Recuperado de https://www.cndh.org.mx/sites/all/doc/ Recomendaciones/2017/Rec_2017_015.pdf

23. México. Comisión Estatal de Derechos Humanos. Recomendación N. ${ }^{\circ}$ 18. (25 de mayo de 2017). Recuperado de https://www.cndh.org.mx/sites/all/doc/ Recomendaciones/2017/Rec_2017_018.pdf

24. México. Comisión Nacional de Búsqueda (CNB). Protocolo Homologado para la Búsqueda de Personas Desaparecidas y No Localizadas. (5 de mayo de 2020). Recuperado de https://www.gob.mx/cnb/documentos/proyecto-del-phb-para-procesode-participacion-y-fortalecimiento

25. México. Conferencia Nacional de Procuración de Justicia. Protocolo Homologado de Investigación para los Delitos de Desaparición Forzada de Personas y Cometida por Particulares. (16 de julio de 2018). Recuperado de http://aplicaciones. pgr.gob.mx/normatecasustantiva/Normateca $\% 20$ Sustantiva/Protocolo $\% 20 \mathrm{de} \% 20$ Desaparici\%C3\%B3n\%20Forzada.pdf

26. México. Fiscalía General de la República. Protocolo Homologado para la Búsqueda de Personas Desaparecidas y la Investigación del Delito de Desaparición Forzada. (15 de octubre de 2015). Recuperado de https:/www.gob.mx/cms/uploads/ attachment/file/342262/Protocolo_Desaparici_n_Forzada_agosto_2015_Espa_ol.pdf

27. México. Presidencia de la República. Comunicado. (24 de junio de 2019$)$. Informe de trabajo del Sistema Nacional de búsqueda. Recuperado de https://www.

[ 96 ] gob.mx/presidencia/prensa/informe-de-trabajo-del-sistema-nacional-de-busqueda

28. México. Secretaría de Gobernación. Comunicado. (12 de junio de 2020). El Gobierno federal reitera el compromiso con la búsqueda de personas desaparecidas y el fortalecimiento del sistema nacional de búsqueda. Recuperado de https:// www.gob.mx/segob/prensa/el-gobierno-federal-reitera-el-compromiso-con-labusqueda-de-personas-desaparecidas-y-el-fortalecimiento-del-sistema-nacional-debusqueda?idiom $=$ es

29. Movimiento por Nuestros Desaparecidos en México (MNDM). (2020, enero 16). Las desapariciones no cesan a dos años de la entrada en vigor de la Ley General de Desaparición. Recuperado de https://movndmx.org/las-desapariciones-no-cesan-ados-anos-de-la-entrada-en-vigor-de-la-ley-general-de-desaparicion/

30. Movimiento por Nuestros Desaparecidos en México (MNDM). (s. f.). El movimiento y los colectivos. Recuperado de https://movndmx.org/sobre-el-movndmx/

31. Naciones Unidas. Asamblea General. Consejo de Derechos Humanos. AV HRC/27/56. (27 de agosto de 2014). Informe del Relator Especial sobre la promoción de la verdad, la justicia, la reparación y las garantías de no repetición, Pablo de Greiff. Recuperado de https://www.ohchr.org/EN/HRBodies/HRC/RegularSessions/ Session27/Documents/A_HRC_27_56_SPA.doc

32. Naciones Unidas. Consejo de Derechos Humanos. A/HRC/30/38/Add.4. (11 de septiembre de 2015). Reporte del Grupo de Trabajo sobre las desapariciones 
La gobernanza para enfrentar el problema de la desaparición de personas...

forzadas o involuntarias. Recuperado de https://www.hchr.org.mx/images/doc_pub/ Informe-Seguimiento-GTDFI-ONU_Mexico-2015.pdf

33. Pacheco, Alejandro (2014, febrero 10). Rompe organización diálogo con gobierno de Coahuila por operativos mediáticos. SDPnoticias. Recuperado de https:// www.sdpnoticias.com/estados/organizacion-coahuila-gobierno-dialogo-rompe.html

34. Rodríguez, Alberto (2009, septiembre 2). Exigen con plantón localizar a hijos. El Norte. Recuperado de https://busquedas.gruporeforma.com/elnorte/Documento/ Web.aspx?id=1036391 |ArticulosGC_Norte\&url = https://www.elnorte.com/galeria de_fotos/images/1724/3446857.jpg\&text = Exigen + con + plant $\%$ f3n + localizar $+a+$ hijos\&tit $=$

35. Saldivia Menajovsky, Laura. (2017). Subordinaciones invertidas: sobre el derecho a la identidad de género. Buenos Aires y México, D. F.: Universidad Nacional de Genera Sarmiento, Universidad Nacional Autónoma de México.

36. Sánchez, Víctor Manuel; Pérez, Manuel y Verástegui, Jorge. (2018). Formación y desarrollo de los colectivos de búsqueda de personas desaparecidas en Coahuila: lecciones para el futuro. Seminario sobre Violencia y Paz El Colegio de México. Recuperado de https:/violenciaypaz.colmex.mx/assets/docs_pubs/original/29/ Formacion_y_desarrollo_de_los_colectivos.pdf?1580251978

37. Secretaría de Gobernación. (2020, julio 13). Gobernación y la CNB presentan el informe relativo a la búsqueda, identificación y registro de personas desaparecidas y no localizadas. Recuperado de https:/www.gob.mx/segob/prensa/gobernacion-y-lacnb-presentan-el-informe-relativo-a-la-busqueda-identificacion-y-registro-de-personasdesaparecidas-y-no-localizadas

38. Subirats, Joan (2010). Si la respuesta es gobernanza, ¿cuál es la pregunta? Ekonomiaz, 74, pp. 16-35. Recuperado de https://www.euskadi.eus/web01-a2reveko/ es/k86aEkonomiazWar/ekonomiaz/abrirArticulo? idpubl $=69$ \& registro $=1041$

39. Tapia Gómez, Ariel Alejandro (2007). Después del 11-M: la movilización de las víctimas, ¿modelo europeo de política victimal: las gobernanzas? En: Universidad Externado de Colombia. Cátedra Unesco. Derechos humanos y violencia: gobierno y gobernanza el desplazamiento forzado interno en Colombia: un desafío a los derechos humanos (pp. 323-351). Recuperado de https://www.uexternado.edu.co/ wp-content/uploads/2017/03/Catedra-Unesco-1.pdf

40. Turati, Marcela (2012, diciembre 19). Cumple ONG tres años de hacer visibles a los desaparecidos. Proceso. Recuperado de https://www.proceso.com.mx/328291/ cumple-ong-tres-anos-de-hacer-visibles-a-los-desparecidos

41. Villarreal Martínez, María Teresa (2014). Respuestas ciudadanas ante la desaparición de personas en México (2000-2013). Espacios Públicos, 17 (39), pp. 105-135.

42. Zurbriggen, Cristina (2011). Gobernanza: una mirada desde América Latina. Perfiles Latinoamericanos, 19 (38), pp. 39-64. 